\title{
Effect of sildenafil citrate on the cardiovascular system
}

K. Shinlapawittayatorn, S. Chattipakorn and N. Chattipakorn
Cardiac Electrophysiology Unit, Faculty of Medicine,

Chiang Mai University, Chiang Mai, Thailand

\section{Correspondence \\ N. Chattipakorn \\ Cardiac Electrophysiology Unit \\ Faculty of Medicine \\ Chiang Mai University \\ Chiang Mai \\ Thailand \\ Fax: +66-53-94-5365 \\ E-mail:nchattip@mail.med.cmu.ac.th \\ Research supported in part by the Thailand Research Fund (TRF) grant RSA4680010 (N. Chattipakorn) and MRG 4680144 (S. Chattipakorn) and the funding from the China Medical Board, Faculty of Medicine, Chiang Mai University (N. Chattipakorn and K. Shinlapawittayatorn)}

Received November 26, 2004 Accepted April 18, 2005

\begin{abstract}
Sildenafil citrate is a drug commonly used to manage erectile dysfunction. It is designated chemically as 1-[[3-(6,7-dihydro-1-methyl-7oxo-3-propyl-1 $H$-pyrazolo[4,3- $d$ ]pyrimidin-5-yl)-4 ethoxyphenyl] sulfonyl]-4-methylpiperazine citrate $\left(\mathrm{C}_{22} \mathrm{H}_{30} \mathrm{~N}_{6} \mathrm{O}_{4} \mathrm{~S}\right)$. It is a highly selective inhibitor of cyclic guanine monophosphate-specific phosphodiesterase type 5. In late March through mid-November 1998, the US Food and Drug Administration (FDA) published a report on 130 confirmed deaths among men (mean age, 64 years) who received prescriptions for sildenafil citrate, a period during which $>6$ million outpatient prescriptions (representing about 50 million tablets) were dispensed. The US FDA recently reported that significant cardiovascular events, including sudden cardiac death, have occurred in men with erectile dysfunction who were taking sildenafil citrate. These reports have raised concerns that sildenafil citrate may increase the risk of cardiovascular events, particularly fatal arrhythmias, in patients with cardiovascular disease. In the past few years, the cardiac electrophysiological effects of sildenafil citrate have been investigated extensively in both animal and clinical studies. According to extensive data available to date, sildenafil citrate has been shown to pose minimal cardiovascular risks to healthy people taking this drug. Some precautions are needed for patients with cardiovascular diseases. However, the only absolute contraindication for sildenafil citrate is the concurrent use of nitrates. This article is intended to review sildenafil citrate's cardiovascular effects, as well as current debates about its arrhythmogenic effects.
\end{abstract}

\section{Introduction}

Sildenafil citrate was the first oral drug approved for the treatment of erectile dysfunction (ED), which is frequently observed in men with cardiovascular disease (1). ED is defined as the inability to achieve and/or maintain an erection sufficient for satisfactory sexual activity (2). The prevalence of moderate to complete ED has been reported
Key words

- Sildenafil citrate

- Erectile dysfunction

- Sudden cardiac death

- Cardiovascular disease

- Phosphodiesterase inhibitor

- Cardioprotection to be $>30 \%$ in men aged 40 to 70 years (3). Since the approval of sildenafil citrate, several reports of sudden death among patients treated with this drug have raised some concerns regarding its safety in patients with coronary artery disease (4). In the past few years, the cardiovascular effects of sildenafil citrate have been investigated extensively in both animal and clinical studies. In this article we shall review these studies, as well as 
the current debate about sildenafil citrate's arrhythmogenic effects.

\section{Erectile dysfunction and cardiovascular disease}

ED is a common health concern among patients with cardiovascular disease. According to the Massachusetts Male Aging Study, $34.8 \%$ of men aged 40 to 70 years have moderate to complete ED, and $15 \%$ of men aged 70 have complete ED (3). The risk of ED has been shown to markedly increase with age, with a high prevalence of ED found in patients with cardiovascular disease (3). Greenstein and colleagues (5) have shown that there is a significant correlation between the severity of ED and the number of vessels involved in patients with coronary artery disease (CAD). The age-adjusted prevalence of complete ED has been reported to be 1.5 times higher in men with hypertension than in the entire population studied (3). Epidemiologic studies have reported that ED is commonly found in smokers, diabetics and patients with hypercholesterolemia; thus, ED shares important risk factors with CAD (6). A report by Khan and colleagues (7) also found that patients with CAD and peripheral vascular disease have an increased prevalence of ED.

\section{Sildenafil citrate and erectile dysfunction}

ED is considered to be a significant medical condition because it can lead to a loss of self-esteem, frustration, depression, and difficulty with disruption of sexual relationships (8). Increasing attention has recently been focused on ED due to the advent of effective oral treatments. Although ED was once diagnosed and treated primarily by urologists, primary care physicians and other specialists such as cardiologists now write $\sim 80 \%$ of the prescriptions for sildenafil citrate, the most popular drug used to treat this condition (9).

Sildenafil citrate is a useful tool for the treatment of ED because it selectively inhibits phosphodiesterase type 5 (PDE-5) (10), which inactivates cyclic guanine monophosphate (cGMP), the mediator of smooth muscle relaxation in the corpus cavernosum. By selectively inhibiting cGMP catabolism in cavernosal smooth-muscle cells (10), sildenafil citrate can restore the natural erectile response to sexual stimulation without causing erections in the absence of such stimulation. Sildenafil citrate is rapidly absorbed, with maximal plasma concentrations occurring within $1 \mathrm{~h}$ after oral administration and a mean terminal half-life of 3 to $5 \mathrm{~h}$ (10). Sildenafil citrate has been shown to be an effective treatment for ED. However, after sildenafil citrate was approved by the US Food and Drug Administration (FDA) in 1998, several deaths were reported in patients taking sildenafil citrate. It was generally assumed that they were related to an underlying disease (e.g., ischemia) and not to a specific drug effect (11). Nevertheless, these reports raised concerns that sildenafil citrate may increase the risk of cardiovascular events in men with ED and cardiovascular disease (12), which led to many basic and clinical investigations of the adverse cardiovascular effects of this drug (12).

\section{Use of sildenafil citrate in patients with cardiovascular disease}

Sildenafil citrate is a cGMP-specific PDE5 inhibitor (10). PDE-5, which is located primarily in the cavernous body, thrombocytes and vascular smooth muscle cells, degrades cGMP (13). Thus, by inhibiting PDE5 , sildenafil citrate selectively increases cGMP levels (10). It shows far less affinity for other phosphodiesterase isozymes, including PDE-1, which is abundant in ventricular myocytes (14). However, concern about adverse cardiovascular effects remains (15) since PDE-5 inhibitors promote vasodi- 
lation, and thus have the potential to cause hypotension. This concern has been greatest for elderly patients with pre-existing cardiovascular disease. Mittleman and colleagues (16) reviewed the clinical database for this drug, which supports its cardiovascular safety in a wide range of patients. During placebocontrolled trials, the rate of myocardial infarction (MI) or cardiovascular death was 0.91 (95\% CI: $0.52-1.48$ ) per 100 personyears (PY) of follow-up among sildenafil citrate-treated patients compared with 0.84 (95\% CI: 0.39-1.60) per 100 PY of followup among placebo-treated patients. The relative risk of MI or cardiovascular death was 1.08 (95\% CI: 0.45-2.77) for sildenafil citrate compared with placebo $(\mathrm{P}=0.88)$. During open-label studies, the rate of MI or cardiovascular death was 0.56 (95\% CI: 0.44$0.72)$ per $100 \mathrm{PY}$ of follow-up. This analysis demonstrated that rates of $\mathrm{MI}$ and cardiovascular death are low and comparable between men treated with sildenafil and those treated with placebo, suggesting that the use of sildenafil citrate is not associated with an increase in the risk of MI or cardiovascular death (16). Manfroi and colleagues (17) studied male patients who were referred for coronary angiography with a diagnosis of chronic stable angina. Hemodynamic measurements were taken during right and left heart catheterization in the basal state, and $60 \mathrm{~min}$ after $50 \mathrm{mg}$ of oral sildenafil. A single oral dose of sildenafil citrate had no significant hemodynamic effects in supine patients with stable angina and, thus, the authors concluded that isolated administration of sildenafil citrate does not appear to be associated with adverse cardiovascular effects (17). The ACC/AHA consensus statement recommended that patients taking sildenafil citrate with combinations of antihypertensive drugs (such as calcium-channel blockers, ß-blockers, diuretics, and angiotensin-converting enzyme inhibitors) be alerted to the possibility of hypotension, particularly patients with congestive heart failure (18). The Princeton Consensus Panel concluded that patients with well-controlled hypertension can be safely managed with approved medical treatments for ED (12). However, concomitant use of nitrates is considered to be an absolute contraindication for the use of sildenafil citrate (19). Nitrates are prescribed in several different forms, including sublingual nitroglycerin, oral isosorbide mononitrate or dinitrate, nitropatch, and nitropaste, all of which have been associated with a prolonged decrease in blood pressure when used concomitantly with sildenafil citrate (19). Nitrates are metabolized in vessel walls, where they release nitric oxide. Sildenafil citrate prolongs the vasodilatory effects of nitrates by decreasing the breakdown of nitric oxide's main effector, cGMP. It is not known how much time must elapse between administration of sildenafil citrate and administration of nitrates to avoid significant hypotensive effects (19), but it has been suggested to assume an interval of at least $24 \mathrm{~h}$ (19). Nitroprusside also causes vasodilatation by nonenzymatic release of nitric oxide, and thus is predicted to have a synergistic hypotensive effect with sildenafil citrate (19).

\section{Effects of sildenafil citrate on cardiac contractility, blood pressure and heart rate}

Sildenafil citrate belongs to a class of compounds called PDE inhibitors. PDEs comprise a diverse family of enzymes that hydrolyze cyclic nucleotides (cAMP and cGMP) and therefore play a critical role in the modulation of second messenger signaling pathways (13). Sildenafil citrate is a highly selective ( 4,000-fold) inhibitor of human PDE-5 over human PDE-3 (19). This is important because inhibitors of PDE-3 (the isozyme involved in the regulation of cardiac contractility), such as milrinone, vesnarinone and enoximone, which have been used in patients with heart failure, are 
generally associated with an increased incidence of cardiac arrhythmias and other serious side effects (20). The cardiotoxic effects of PDE-3 inhibitors are thought to be related to an increase in intracellular cAMP in the myocardium $(21,22)$. However, PDE-5 is not present in cardiac myocytes (19). Corbin and colleagues (23) demonstrated in both dog and human hearts that sildenafil citrate was unlikely to directly produce an inotropic effect on cardiac muscle.

Systemic and pulmonary arterial and venous smooth muscle cells contain PDE-5. However, sildenafil citrate causes only a mild and transient decrease in blood pressure (8-10 $\mathrm{mmHg}$ for systolic blood pressure and 5-6 $\mathrm{mmHg}$ for diastolic blood pressure) (19). The peak effects are evident $1 \mathrm{~h}$ after the dose is given and last for approximately $4 \mathrm{~h}$ (19). Heart rate and cardiac output are not significantly affected. Along with a mild decrease in systemic vascular resistance and afterload, there is also a mild decrease in preload and stroke volume due to venous vasodilatation. These effects are not dependent upon age or dose (within the range of 25 to $800 \mathrm{mg}$ ) (19). In a study of patients with severe coronary artery disease, Herrmann and colleagues (24) confirmed that the hemodynamic effects of sildenafil citrate (when taken alone) are not associated with clinically significant hypotension.

\section{Effects of sildenafil citrate on central hemodynamics and peripheral vasculature}

In normal volunteers, no significant changes in cardiac index were evident up to $12 \mathrm{~h}$ after administration of oral sildenafil citrate (100 to $200 \mathrm{mg}$ ) or intravenous sildenafil citrate (20 to $80 \mathrm{mg}$ ) (19). Significant decreases in the systemic vascular resistance index were reported at the end of intravenous sildenafil citrate infusion (20 to 80 $\mathrm{mg}$ ), when plasma concentrations were highest (19). Sildenafil citrate has both vasodila- tor and venodilator effects on the peripheral vasculature (19). In 8 patients with stable angina, intravenous sildenafil citrate reduced systemic and pulmonary arterial pressures, as well as cardiac output, by 8,25 , and $7 \%$, respectively, consistent with its mixed arterial (systemic and pulmonary hypotension) and venous (drop in stroke volume secondary to decreased preload) vasodilator effects (25).

Although the therapeutic efficacy of sildenafil citrate in the treatment of ED has been proven, little is known about the potential beneficial effects of sildenafil citrate in other diseases. Studies in rats demonstrated that PDE-5 inhibition with sildenafil attenuates the rise in pulmonary artery pressure and vascular remodeling when given before chronic exposure to hypoxia-induced pulmonary hypertension (26). Likewise, clinical investigations in patients with pulmonary arterial hypertension have shown that sildenafil citrate therapy may be beneficial to patients receiving long-term infusion of epoprostenol $(27,28)$. A recent meta-analysis study has suggested that the validity of the observed effect of sildenafil on pulmonary hypertension is not conclusive due to small participant numbers and inadequate investigation of different disease etiologies. In addition, further studies are needed to investigate the long-term outcome (29).

\section{Sildenafil citrate and sudden cardiac death}

Sudden cardiac death is a major cause of death in many industrialized countries including Thailand $(27,30)$. It is most often caused by a lethal cardiac arrhythmia known as ventricular fibrillation (VF) (27,30-35). VF has been characterized as a rapid, disorganized, and asynchronous contraction of ventricular muscle, which causes the failure of the pumping function of the heart, leading to vital organ failure and causing death within minutes (36-39). According to a report by 
the World Health Organization, the annual incidence of sudden cardiac death in industrialized countries ranges from 10 to $32 \%$ of natural deaths, depending upon the time that elapses from the onset of symptoms to death, making it the most common form of fatal cardiac disease (40). In the past few years, a growing number of studies have reported that this lethal arrhythmia led to sudden cardiac death in many middle-aged men treated with sildenafil citrate (41).

Post-marketing surveillance data after the approval of sildenafil citrate by the US FDA revealed significant cardiovascular problems, including sudden cardiac death, related to the use of sildenafil citrate (4). As of February 1999, the US FDA had received 401 reports of death among men who had received a prescription for sildenafil citrate over the prior 10 to 11 months. These included 219 cardiovascular events (MI, arrhythmia, cardiac arrest, collapse), 140 sudden deaths, and 18 cerebrovascular accidents. The reporting period represented about 4 million to 5 million men and approximately 9 million prescriptions, which translates to approximately 8.5 deaths per million men per month (4). However, it was determined from an analysis of adverse events reported to the FDA between March 1998 and August 1999 that important data were missing from these reports, such as medical histories, cause of death and sildenafil citrate dosing (42).

As of September 30, 2001, Pfizer's clinical safety database contained information on the extent of exposure to sildenafil citrate from 124 completed and ongoing doubleblind and open-label clinical trials involving 5054 placebo-treated and 6896 sildenafil citrate-treated patients, representing $2593 \mathrm{PY}$ of observation (43). Analysis of these data revealed that the overall MI incidence rate was similar in placebo-treated $(0.95 / 100 \mathrm{PY})$ and sildenafil citrate-treated patients $(0.85 /$ 100 PY; $\mathrm{P}=0.801)$. For the open-label studies, analysis of data from patients repre- senting 10,859 PY of sildenafil citrate exposure demonstrated an MI incidence rate of $0.53 / 100 \mathrm{PY}$. The overall MI rate for doubleblind and open-label sildenafil citrate-treated patients was 0.58/100 PY. Similar rates have been reported in a number of epidemiologic studies (44). The database also contains (as of September 30, 2001) reports of 5 deaths (from all causes) among double-blind placebo-treated patients and 9 deaths among sildenafil citrate-treated patients. This corresponds to all-cause mortality rates of 0.53 / $100 \mathrm{PY}$ and $0.55 / 100 \mathrm{PY}$, respectively $(\mathrm{P}=$ 0.945 ). The overall (double-blind and openlabel) mortality rate among sildenafil citrate-treated patients was $0.37 / 100 \mathrm{PY}$, which is lower than that $(0.66 / 100 \mathrm{PY})$ calculated for men aged 40 to 64 years in the US for 1999. These results clearly show that the incidences of MI and all-cause mortality among patients who received double-blind and/or open-label sildenafil citrate treatment are similar to those observed among patients who received placebo, or in men in the same age cohort of the general population (43). Carson III (45) reported that the incidence of adverse cardiovascular events in patients taking sildenafil does not differ from that for the general population.

\section{Cardiac electrophysiological effects of sildenafil citrate}

In the past few years, the cardiac electrophysiological effects of sildenafil citrate have been investigated extensively (46). Geelen and colleagues (46) demonstrated that sildenafil citrate induces a dose-dependent block of the rapid component of the delayed rectifier potassium current $\left(I_{\mathrm{Kr}}\right)$. They also reported that sildenafil citrate can have an action similar to that of class III antiarrhythmic drugs (46). These effects are observed at concentrations that may be found in conditions of impaired drug elimination such as renal or hepatic insufficiency, during coadministration of another CYP3A4 inhibi- 
tor, or after drug overdose (11). Prolonged cardiac repolarization caused by sildenafil citrate could result in malignant ventricular arrhythmias and lead to sudden cardiac death in some of these patients (11). Swissa and colleagues (47) demonstrated that a combination of sildenafil citrate and a nitric oxide donor increases ventricular tachyarrhythmia/ VF vulnerability in the normal right ventricle of swine.

Although many reports have demonstrated the arrhythmogenic effects of sildenafil citrate, some studies have reported otherwise. Vardi and colleagues (48) showed that sildenafil citrate does not alter the hemodynamic responses to exercise or change the incidence of ventricular arrhythmias in men with cardiovascular disease and ED. Chiang and colleagues (49) found that sildenafil citrate at concentrations up to $30 \mu \mathrm{M}$ has no significant effect on either the rapid $\left(I_{\mathrm{Kr}}\right)$ or the slow $\left(I_{\mathrm{Ks}}\right)$ components of the delayed rectifier potassium currents in guinea pig ventricular myocytes. They also found that sildenafil citrate dose-dependently blocks L-type $\mathrm{Ca}^{2+}$ currents $\left(I_{\mathrm{Ca}, \mathrm{L}}\right)$, but has no effect on persistent $\mathrm{Na}^{+}$currents. They concluded that sildenafil citrate does not prolong cardiac repolarization. Instead, in supra-therapeutic concentrations, it accelerates cardiac repolarization, presumably via its blocking effect on $I_{\mathrm{Ca}, \mathrm{L}}$ (49). Recent studies have also demonstrated that oral administration of $50 \mathrm{mg}$ sildenafil citrate does not affect QT dynamic properties (50). Furthermore, Nagy and colleagues (51) recently reported that sildenafil citrate reduces arrhythmia severity during ischemia $24 \mathrm{~h}$ after oral administration in dogs.

\section{Cardioprotective effects of sildenafil citrate}

Ischemic preconditioning results in powerful cardioprotective effects (52). Repeated brief episodes of ischemia initiate a cascade of intracellular signaling events which help prevent future myocardial infraction and stunning (52). After initial observation, this phenomenon, termed "myocardial preconditioning", was studied intensively to try to understand its cellular mechanisms and apply this knowledge towards protection of the human heart from ischemic heart disease. Current data suggest that sildenafil citrate has a preconditioning-like cardioprotective effect in the rabbit, rat and mouse heart (53). Das and colleagues (54) reported that sildenafil citrate at a much lower dose $(0.05 \mathrm{mg} /$ $\mathrm{kg}$ ) provides significant cardioprotection in isolated perfused rat hearts following global ischemic-reperfusion. They observed an improved post-ischemic recovery of ventricular function, a reduction in the incidence of $\mathrm{VF}$, and a decrease in MI. At higher doses, sildenafil caused a significant increase in the incidence of VF, while at very low doses it had no effect on cardiac function (54). However, a study by Reffelmann and Kloner (55) demonstrated otherwise. In their report, they did not find a decrease in myocardial necrosis following ischemia-reperfusion in a rabbit model. The reason for these negative results was not clear. The only noticeable difference in the experimental procedure was a considerably longer drug infusion time $(\sim 5$ min) in the study by Reffelmann and Kloner (55) as compared to that used by Ockaili and colleagues (56) ( 1 min), which could potentially affect the hemodynamic response prior to ischemia.

\section{Signaling mechanisms in sildenafil-induced cardioprotection}

Although sildenafil citrate has been shown to have a powerful preconditioninglike cardioprotective effects in animal models of ischemia-reperfusion injury, the precise cellular mechanism underlying these effects remains unclear. The sildenafil citrate-induced cardioprotective effect against ischemia-reperfusion injury is dependent upon the opening of mitochondrial ATP- 
sensitive potassium channels $\left(\right.$ mitoK $_{\mathrm{ATP}}$ channels) in rabbits (56). It has been proposed that the vasodilatory action of sildenafil citrate could potentially cause the release of endogenous mediators of preconditioning, such as adenosine or bradykinin from endothelial cells, which may trigger a signaling cascade (through the action of kinases) and the release of nitric oxide (56). Generation of nitric oxide could potentially activate guanylate cyclase, resulting in an enhanced formation of cGMP (57). cGMP may activate protein kinase $\mathrm{G}$, which could then open mitoK $\mathrm{K}_{\mathrm{ATP}}$ channels, resulting in both acute and delayed cardioprotective effects (58). Mitochondria are known to play an essential role in cell survival via ATP synthesis and maintenance of $\mathrm{Ca}^{2+}$ homeostasis (59). Opening mitoK $\mathrm{K}_{\mathrm{ATP}}$ channels partially compensates the membrane potential, which enables additional protons to be pumped out to form an $\mathrm{H}^{+}$electrochemical gradient to drive both ATP synthesis and $\mathrm{Ca}^{2+}$ transport. Recently, Das and colleagues (60) reported that protein kinase $\mathrm{C}$ also plays an essential role in sildenafil-induced cardioprotection in rabbits.

We conclude that, in view of the increasing incidence of sudden cardiac death in ED patients treated with sildenafil citrate, it is essential to understand how this drug affects the entire cardiovascular system, especially the heart. According to extensive data available to date, sildenafil citrate has been shown to pose minimal cardiovascular risks to healthy people taking this drug. Some precautions, however, are needed for patients with cardiovascular disease. Further clinical and basic investigation on the cardiovascular effects of sildenafil citrate is needed to assure proper treatment of ED in patients with cardiovascular disease.

\section{References}

1. Chew KK, Earle CM, Stuckey BG, Jamrozik K \& Keogh EJ (2000). Erectile dysfunction in general medicine practice: prevalence and clinical correlates. International Journal of Impotence Research, 12: 41-45.

2. Laumann EO, Paik A \& Rosen RC (1999). Sexual dysfunction in the United States: prevalence and predictors. Journal of the American Medical Association, 281: 537-544.

3. Feldman HA, Goldstein I, Hatzichristou DG, Krane RJ \& McKinlay JB (1994). Impotence and its medical and psychosocial correlates: results of the Massachusetts Male Aging Study. Journal of Urology, 151: 54-61.

4. Kloner RA (2000). Cardiovascular risk and sildenafil. American Journal of Cardiology, 86: 57F-61F.

5. Greenstein A, Chen J, Miller H, Matzkin H, Villa Y \& Braf Z (1997). Does severity of ischemic coronary disease correlate with erectile function? International Journal of Impotence Research, 9: 123-126.

6. Israilov S, Baniel J, Shmueli J, Niv E, Engelstein D, Segenreich E \& Livne PM (2004). Treatment program for erectile dysfunction in patients with cardiovascular diseases. American Journal of Cardiology, 93: 689-693.

7. Khan MA, Ledda A, Mikhailidis DP, Rosano G, Vale J, Vickers M \& Consensus Writing Committee (2002). Second Consensus Conference on Cardiovascular Risk Factors and Erectile Dysfunction. Current Medical Research and Opinion, 18: 33-35.

8. Lue TF (2000). Erectile dysfunction. New England Journal of Medicine, 342: 1802-1813.

9. Kloner RA \& Jarow JP (1999). Erectile dysfunction and sildenafil citrate and cardiologists. American Journal of Cardiology, 83: 576-
582.

10. Goldstein I, Lue TF, Padma-Nathan H, Rosen RC, Steers WD \& Wicker PA (1998). Oral sildenafil in the treatment of erectile dysfunction. Sildenafil Study Group. New England Journal of Medicine, 338: 1397-1404.

11. Shakir SA, Wilton LV, Boshier A, Layton D \& Heeley E (2001). Cardiovascular events in users of sildenafil: results from first phase of prescription event monitoring in England. British Medical Journal, 322: 651-652.

12. DeBusk R, Drory Y, Goldstein I et al. (2000). Management of sexual dysfunction in patients with cardiovascular disease: recommendations of the Princeton Consensus Panel. American Journal of Cardiology, 86: 62F-68F.

13. Beavo JA (1995). Cyclic nucleotide phosphodiesterases: functional implications of multiple isoforms. Physiological Reviews, 75: 725748.

14. Wallis RM, Corbin JD, Francis SH \& Ellis P (1999). Tissue distribution of phosphodiesterase families and the effects of sildenafil on tissue cyclic nucleotides, platelet function, and the contractile responses of trabeculae carneae and aortic rings in vitro. American Journal of Cardiology, 83: 3C-12C.

15. Arora RR, Timoney M \& Melilli L (1999). Acute myocardial infarction after the use of sildenafil. New England Journal of Medicine, 341: 700.

16. Mittleman MA, Glasser DB \& Orazem J (2003). Clinical trials of sildenafil citrate (Viagra) demonstrate no increase in risk of myocardial infarction and cardiovascular death compared with placebo. International Journal of Clinical Practice, 57: 597-600. 
17. Manfroi WC, Caramori PR, Zago AJ, Melchior R, Zen V, Accordi M, Gutierres D \& Noer C (2003). Hemodynamic effects of sildenafil in patients with stable ischemic heart disease. International Journal of Cardiology, 90: 153-157.

18. Cheitlin MD, Hutter Jr AM, Brindis RG, Ganz P, Kaul S, Russell Jr RO \& Zusman RM (1999). Use of sildenafil (Viagra) in patients with cardiovascular disease. Technology and Practice Executive Committee. Circulation, 99: 168-177.

19. Cheitlin MD, Hutter Jr AM, Brindis RG, Ganz P, Kaul S, Russell Jr RO \& Zusman RM (1999). ACC/AHA expert consensus document. Use of sildenafil (Viagra) in patients with cardiovascular disease. American College of Cardiology/American Heart Association. Journal of the American College of Cardiology, 33: 273-282.

20. Packer M, Carver JR, Rodeheffer RJ et al. (1991). Effect of oral milrinone on mortality in severe chronic heart failure. The Promise Study Research Group. New England Journal of Medicine, 325: 1468-1475.

21. Degerman E, Belfrage P \& Manganiello VC (1997). Structure, localization, and regulation of cGMP-inhibited phosphodiesterase (PDE3). Journal of Biological Chemistry, 272: 6823-6826.

22. Nony $\mathrm{P}$, Boissel JP, Lievre M, Leizorovicz A, Haugh MC, Fareh S \& de Breyne B (1994). Evaluation of the effect of phosphodiesterase inhibitors on mortality in chronic heart failure patients. A metaanalysis. European Journal of Clinical Pharmacology, 46: 191-196.

23. Corbin J, Rannels S, Neal D, Chang P, Grimes K, Beasley A \& Francis S (2003). Sildenafil citrate does not affect cardiac contractility in human or dog heart. Current Medical Research and Opinion, 19: $747-752$

24. Herrmann HC, Chang G, Klugherz BD \& Mahoney PD (2000). Hemodynamic effects of sildenafil in men with severe coronary artery disease. New England Journal of Medicine, 342: 1622-1626.

25. Rajfer J, Aronson WJ, Bush PA, Dorey FJ \& Ignarro LJ (1992). Nitric oxide as a mediator of relaxation of the corpus cavernosum in response to nonadrenergic, noncholinergic neurotransmission. New England Journal of Medicine, 326: 90-94.

26. Sebkhi A, Strange JW, Phillips SC, Wharton J \& Wilkins MR (2003). Phosphodiesterase type 5 as a target for the treatment of hypoxiainduced pulmonary hypertension. Circulation, 107: 3230-3235.

27. Stiebellehner L, Petkov V, Vonbank K, Funk G, Schenk P, Ziesche R \& Block LH (2003). Long-term treatment with oral sildenafil in addition to continuous IV epoprostenol in patients with pulmonary arterial hypertension. Chest, 123: 1293-1295.

28. Wilkens H, Guth A, Konig J, Forestier N, Cremers B, Hennen B, Bohm M \& Sybrecht GW (2001). Effect of inhaled iloprost plus oral sildenafil in patients with primary pulmonary hypertension. Circulation, 104: 1218-1222.

29. Kanthapillai P, Lasserson T \& Walters E (2004). Sildenafil for pulmonary hypertension. Cochrane Database of Systemic Reviews, CD003562.

30. Nademanee K, Veerakul G, Nimmannit S et al. (1997). Arrhythmogenic marker for the sudden unexplained death syndrome in Thai men. Circulation, 96: 2595-2600.

31. Chattipakorn N, Fotuhi PC, Zheng X \& Ideker RE (2000). Left ventricular apex ablation decreases the upper limit of vulnerability. Circulation, 101: 2458-2460.

32. Chattipakorn N, Fotuhi PC, Sreenan CM, White JB \& Ideker RE (2000). Pacing after shocks stronger than the upper limit of vulnerability: impact on fibrillation induction. Circulation, 101: 1337-1343.

33. Chattipakorn N, Rogers JM \& Ideker RE (2000). Influence of postshock epicardial activation patterns on initiation of ventricular fibrillation by upper limit of vulnerability shocks. Circulation, 101:
1329-1336.

34. Chattipakorn N, Banville I, Gray RA \& Ideker RE (2001). Mechanism of ventricular defibrillation for near-defibrillation threshold shocks: a whole-heart optical mapping study in swine. Circulation, 104: 13131319.

35. Chattipakorn N, Fotuhi PC, Chattipakorn SC \& Ideker RE (2003) Three-dimensional mapping of earliest activation after near-threshold ventricular defibrillation shocks. Journal of Cardiovascular Electrophysiology, 14: 65-69.

36. Fish FA (2004). Ventricular fibrillation: basic concepts. Pediatric Clinics of North America, 51: 1211-1221.

37. Chattipakorn N, Fotuhi PC \& Ideker RE (2000). Pacing following shocks stronger than the defibrillation threshold: impact on defibrillation outcome. Journal of Cardiovascular Electrophysiology, 11: 1022-1028.

38. Chattipakorn N, Fotuhi PC \& Ideker RE (2000). Prediction of defibrillation outcome by epicardial activation patterns following shocks near the defibrillation threshold. Journal of Cardiovascular Electrophysiology, 11: 1014-1021.

39. Chattipakorn N, Banville I, Gray RA \& Ideker RE (2004). Effects of shock strengths on ventricular defibrillation failure. Cardiovascular Research, 61: 39-44.

40. Brindis RG \& Kloner RA (2003). Sildenafil in patients with cardiovascular disease. American Journal of Cardiology, 92: 26M-36M.

41. Murray CJ \& Lopez AD (1997). Alternative projections of mortality and disability by cause 1990-2020: Global Burden of Disease Study. Lancet, 349: 1498-1504.

42. Alloggiamento T, Zipp C, Raxwal VK, Ashley E, Dey S, Levine S \& Froelicher VF (2001). Sex, the heart, and sildenafil. Current Problems in Cardiology, 26: 388-415.

43. Padma-Nathan $H$, Eardley I, Kloner RA, Laties AM \& Montorsi $F$ (2002). A 4-year update on the safety of sildenafil citrate (Viagra). Urology, 60: 67-90.

44. McGovern PG, Jacobs Jr DR, Shahar E, Arnett DK, Folsom AR, Blackburn H \& Luepker RV (2001). Trends in acute coronary heart disease mortality, morbidity, and medical care from 1985 through 1997: the Minnesota heart survey. Circulation, 104: 19-24.

45. Carson III CC (2003). Sildenafil: a 4-year update in the treatment of 20 million erectile dysfunction patients. Current Urology Reports, 4: 488-496.

46. Geelen P, Drolet B, Rail J, Berube J, Daleau P, Rousseau G, Cardinal R, O'Hara GE \& Turgeon J (2000). Sildenafil (Viagra) prolongs cardiac repolarization by blocking the rapid component of the delayed rectifier potassium current. Circulation, 102: 275-277.

47. Swissa M, Ohara T, Lee MH, Kaul S, Shah PK, Hayashi H, Chen PS \& Karagueuzian HS (2002). Sildenafil-nitric oxide donor combination promotes ventricular tachyarrhythmias in the swine right ventricle. American Journal of Physiology, 282: H1787-H1792.

48. Vardi Y, Bulus M, Reisner S, Nassar S, Aboud L, Sprecher E \& Gruenwald I (2003). Effects of sildenafil citrate (Viagra) on hemodynamic parameters during exercise testing and occurrence of ventricular arrhythmias in patients with erectile dysfunction and cardiovascular disease. European Urology, 43: 544-551.

49. Chiang CE, Luk HN, Wang TM \& Ding PY (2002). Effects of sildenafil on cardiac repolarization. Cardiovascular Research, 55: 290-299.

50. Kaya D, Guler C, Esen AM, Barutcu I \& Dincel C (2004). Sildenafil citrate does not alter ventricular repolarization properties: novel evidence from dynamic QT analysis. Annals of Noninvasive Electrocardiology, 9: 228-233.

51. Nagy O, Hajnal A, Parratt JR \& Vegh A (2004). Sildenafil (Viagra) reduces arrhythmia severity during ischaemia $24 \mathrm{~h}$ after oral admin- 
istration in dogs. British Journal of Pharmacology, 141: 549-551.

52. Murry CE, Jennings RB \& Reimer KA (1986). Preconditioning with ischemia: a delay of lethal cell injury in ischemic myocardium. Circulation, 74: 1124-1136.

53. Salloum F, Yin C, Xi L \& Kukreja RC (2003). Sildenafil induces delayed preconditioning through inducible nitric oxide synthasedependent pathway in mouse heart. Circulation Research, 92: 595597.

54. Das S, Maulik N, Das DK, Kadowitz PJ \& Bivalacqua TJ (2002), Cardioprotection with sildenafil, a selective inhibitor of cyclic 3',5'monophosphate-specific phosphodiesterase 5. Drugs under Experimental and Clinical Research, 28: 213-219.

55. Reffelmann T \& Kloner RA (2003). Effects of sildenafil on myocardial infarct size, microvascular function, and acute ischemic left ventricular dilation. Cardiovascular Research, 59: 441-449.

56. Ockaili R, Salloum F, Hawkins J \& Kukreja RC (2002). Sildenafil
(Viagra) induces powerful cardioprotective effect via opening of mitochondrial K(ATP) channels in rabbits. American Journal of Physiology, 283: H1263-H1269.

57. Wallis RM (1999). The pharmacology of sildenafil, a novel and selective inhibitor of phosphodiesterase (PDE) type 5. Nippon Yakurigaku Zasshi. Japanese Journal of Pharmacology, 114 (Suppl 1): 22P-26P.

58. Zhao TC \& Kukreja RC (2002). Late preconditioning elicited by activation of adenosine $A(3)$ receptor in heart: role of NF-kappa B, iNOS and mitochondrial K(ATP) channel. Journal of Molecular and Cellular Cardiology, 34: 263-277.

59. Gross GJ (2000). The role of mitochondrial KATP channels in cardioprotection. Basic Research in Cardiology, 95: 280-284.

60. Das A, Ockaili R, Salloum F \& Kukreja RC (2004). Protein kinase C plays an essential role in sildenafil-induced cardioprotection in rabbits. American Journal of Physiology, 286: H1455-H1460. 